\title{
Peningkatan Kelarutan dan Disolusi Ibuprofen melalui Pembentukan Mikropartikel Metode Emulsification-Ionic-Gelation Menggunakan Polivinil Alkohol (PVA) sebagai Polimer dan Tripolifosfat (TPP) sebagai Agen Crosslink
}

\author{
Rival Ferdiansyah, Yola Desnera Putri, Syarif Hamdani, Angga Julianto \\ Sekolah Tinggi Farmasi Indonesia, Bandung, Jawa Barat, Indonesia
}

\begin{abstract}
Abstrak
Ibuprofen dikenal sebagai obat antiinflamasi nonsteroid yang digunakan untuk analgetik dan antipiretik dan termasuk obat dengan kelarutan rendah, tetapi memiliki permeabilitas yang tinggi. Penelitian ini bertujuan untuk menghasilkan ibuprofen dengan kelarutan dan disolusi yang lebih tinggi dengan membentuk mikropartikel menggunakan metode emulsification-ionic gelation. Partikel ibuprofen dikarakterisasi menggunakan Scanning Elektron Microscopy dan Fourier Transform Infrared Spectroscopy (FTIR). Kemudian dilakukan uji kelarutan dan uji disolusi ibuprofen. Pengujian karakteristik menggunakan SE, mikropartikel $\mathrm{pH}$ 2, $\mathrm{pH} 4, \mathrm{pH} 6$ mengalami penurunan ukuran partikel berturut-turut sebesar $97,48 \%, 84 \%$, dan $72 \%$ dari ukuran ibuprofen. Kelarutan ibuprofen setelah proses emulsification-ionic-gelation dalam air pada $\mathrm{pH} 6$ meningkat delapan kali, sedangkan disolusi ibuprofen tertinggi ditunjukkan oleh partikel ibuprofen pada formula 3 yang dapat mendisolusi ibuprofen lebih dari 44\% dalam 30 menit pada media dapar $\mathrm{HCl} 0,1 \mathrm{~N}$ dibandingkan dengan formula yang lain. Kesimpulan yang diperoleh adalah partikel ibuprofen setelah proses emulsification-ionicgelation dapat memperkecil ukuran partikel dan meningkatkan kelarutan tetapi tidak dengan disolusinya.
\end{abstract}

Kata kunci: Ibuprofen, emulsification-ionic-gelation, polivinil alkohol, kelarutan, disolusi

\section{Increasing Solubility and Dissolution of Ibuprofen through the Formation of Microparticles Emulsification-Ionic-Gelation Method using Polyvinyl Alcohol (PVA) as Polymer and Tripolyphosphate (TPP) as Crosslink Agent}

\begin{abstract}
Ibuprofen is known as a nonsteroidal anti-inflammatory drug used for analgesics and antipyretics. It is classified as a drug with low solubility, but high permeability. The aim of this research was to produce higher solubility and dissolution of ibuprofen by forming microparticle which used emulsification ionic gelation method and the influence microparticle formed to penetration of ibuprofen. Ibuprofen particles were characterized by Scanning Electron Microscopy and Fourier Transform Infrared Spectroscopy (FTIR). Then solubility test and ibuprofen dissolution test were carried out. Characteristic test using SEM ibuprofen with $\mathrm{pH} 2, \mathrm{pH} 4, \mathrm{pH} 6$ have decreased in particle size of $97.48 \%, 84 \%$, and $72 \%$ of ibuprofen size, respectively. The solubility of ibuprofen after the emulsification-ionic-gelation process in water at $\mathrm{pH} 6$ increased eight times, and the highest dispersion of ibuprofen was demonstrated by the ibuprofen particles of formula 3 which could disintegrate ibuprofen by more than $44 \%$ in $30 \mathrm{~min}$ in $0.1 \mathrm{~N} \mathrm{HCl}$ buffer media compared with other formulas. It can be concluded that ibuprofen particles after the emulsification-ionic-gelation process can decrease particle size and increase solubility but not by its disolutions.
\end{abstract}

Keyword: Ibuprofen, emulsification-ionic-gelation, polyvinyl alcohol, solubility, dissolution 


\section{Pendahuluan}

Ibuprofen adalah salah satu antiinflamasi nonsteroid yang digunakan untuk analgetik dan antipiretik. Ibuprofen sering digunakan dengan frekuensi pemakaian berulangkali dalam sehari dan dapat menyebabkan efek samping gangguan saluran cerna. Ibuprofen dalam Biopharmaceutics Classification System (BCS) termasuk kelas II atau obat dengan kelarutan rendah, tetapi memiliki permeabilitas yang tinggi (Dressman dan Buttler, 2001). Obat yang mempunyai sifat demikian, absorpsinya cenderung tidak teratur, lambat dan tidak sempurna sehingga diperlukan upaya untuk meningkatkan kelarutan melalui pengembangan formulasi agar obat dapat cepat terlepas dari sediaan (terlarut dalam cairan gastrointestinal, selanjutnya dapat dengan cepat diabsorpsi dan cepat menimbulkan efek). Mengatasi permasalahan ibuprofen tersebut dan meningkatkan efikasi, ibuprofen dapat dibuat melalui suatu sistem penghantaran baru dengan teknik mikropartikel (Agnihotri et al, 2004).

Mikropartikel adalah partikel dengan diameter 1 sampai $1000 \mu \mathrm{m}$, tidak berpengaruh pada ketepatan stuktur di dalam dan di luar partikel. Kategori mikropartikel secara luas adalah "mikrosfer" yang secara spesifik menunjukkan mikropartikel berbentuk bola dan subkategorinya adalah "mikrokapsul" digunakan untuk mikropartikel yang memiliki inti yang dikelilingi suatu materi yang berbeda dari inti tersebut. Inti tersebut dapat berupa padat, cair, ataupun gas.
Penggunaan biodegradable mikrosfer mukoadesif sebagai sistem penghantaran

Obat memiliki keuntungan pengontrolan dan pelepasan obat terus menerus, pemberian yang mudah, dapat biodegradasi, biokompatibilitas, melindungi obat yang bersifat asam dan enzim pada saluran pencernaan dan tidak perlu penggunaan obat sehari-hari. Penggunaan polimer berbeda untuk biodegradasi, beberapa polimer sintetik banyak digunakan.

Pembentukan mikropartikel atau mikronisasi dapat meningkatkan penghantaran obat dalam tubuh. Mikronisasi dilakukan untuk memperluas area partikel per volume solid yang dapat mengontrol laju pelarutan obat dalam tubuh sehingga mengurangi efek samping pada gastrointestinal. Pada pembuatan mikropartikel dengan metode emulsifikasi dibutuhkan polimer dan bahan penyambung silang yang berfungsi sebagai pengeras dan mempertahankan bentukan mikropartikel (Rijal, 2010). Adapun metode yang digunakan dalam penelitian ini yaitu metode emulsification-ionic-gelation. Metode ini memiliki keunggulan yaitu metodenya sederhana, tidak toksik, dilakukan pada temperatur ruangan, ukuran dapat disesuaikan, memiliki kapasitas baik untuk berasosiasi dengan obat makromolekul pada komposisi partikel. Metode emulsifications ionic gelation merupakan pembuatan mikrosfer yang dibuat dari polimer jenis gel dan diproduksi dengan melarutkan polimer dalam larutan berair atau 
mensuspensikan bahan aktif ke dalam campuran (Samad, et al., 2010).

Pada pembuatan mikropartikel dengan metode emulsifikasi gelasi ionik dibutuhkan bahan penyambung silang yang berfungsi sebagai pengeras dan mempertahankan bentuk mikropartikel. Bahan penyambung silang yang sering digunakan untuk pembuatan mikropartikel adalah tripolifosfat (Ko, et al., 2002).

Mikropartikel dapat menjadi penghantaran obat yang akurat, mengurangi konsentrasi obat pada target dan memberikan sistem penghantaran yang efektif untuk zat aktif yang sedikit larut dalam air. Selain itu, sediaan mikropartikel dapat melepaskan lebih dari $80 \%$ zat aktif dalam waktu 10 menit. Mikropartikel dapat digunakan untuk memproduksi obat amorf dengan karakter fisik yang diinginkan dan dapat mengurangi efek samping lokal misalnya iritasi saluran pencernaan pada pemberian oral (Parida, et al., 2013).

Beberapa polimer yang bisa digunakan pada pembuatan mikropartikel antara lain adalah polivinil alkohol (PVA). Untuk tujuan aplikasinya, polimer PVA dimodifikasikan ke bentuk PVA berikatan silang atau kopolimerisasi dengan polimer/monomer (Swasono, dkk., 2006). Mekanisme pembentukan mikropartikel berdasarkan pada interaksi elektrostatik antara gugus polikation pada polimer dan muatan negatif pada polianion seperti tripolifosfat. Terbentuknya gugus kation pada polimer karena adanya gugus anion pada polimer yang berinteraksi dengan asam kuat pada proses pembentukan mikropartikel.

Berdasarkan hal di atas, pada penelitian ini akan dilakukan pembuatan mikropartikel Ibuprofen menggunakan polimer PVA dan crosslinker TPP dengan metode emulsification-ionic-gelation.

\section{Metode}

Alat

Alat yang digunakan dalam penelitian ini adalah Neraca analitik, pengayak mesh no.140, corong buchner, lemari pengering, dissolution tester (Flight Pharmaceutical RC-3), spektrofotometer Uv-Vis (Shimadzu UV1800), spektrofotometer inframerah (Thermo Nicolet i5 ATR iD3), Scanning Electron Microscopy (SEM), homogenizer (Heidolph) dan alat gelas laboratorium lainnya.

Bahan

Bahan yang digunakan dalam penelitian ini adalah Ibuprofen (Shasun), PVA (Brataco), minyak kelapa, asam asetat (Brataco), sodium trifosfat (Brataco), akuades, natrium asetat asam klorida (Brataco), kalium klorida (Brataco), kalium dihidrogen fosfat (Brataco), natrium hidroksida (Brataco), dan washbenzene (Brataco).

Pembuatan Mikropartikel IbuprofenPVA

Pembuatan mikropartikel Ibuprofen-PVA dengan menggunakan metode emulsification-ionic gelation 
Tabel 1. Rancangan formula mikropartikel Ibuprofen-PVA

\begin{tabular}{cccc}
\hline Bahan & \multicolumn{3}{c}{ Formula } \\
\cline { 2 - 4 } & F1 & F2 & F3 \\
\hline Ibuprofen $(\mathrm{g})$ & 0,3 & 0,3 & 0,3 \\
PVA (g) & 0,3 & 0,3 & 0,3 \\
Asam asetat 4\% v/v (mL) & 30 & 10 & 10 \\
Minyak kelapa (mL) & 30 & 30 & 30 \\
Larutan TPP & pH 2 & pH 4 & pH 6 \\
\hline
\end{tabular}

Keterangan : $\mathrm{F}=$ Formula

dengan rancangan formula seperti Tabel 1 .

PVA sebanyak $0,3 \mathrm{~g}$ dilarutkan dalam asam asetat $4 \% 10 \mathrm{~mL}$ sampai larut. Ibuprofen didispersikan dalam larutan PVA kemudian diaduk sampai homogen. Dispersi ibuprofen-kitosan dimasukkan ke dalam fase minyak dan diaduk dengan keceptan $5000 \mathrm{rpm}$ selama 15 menit.

Pembuatan larutan TPP $15 \%$ dibuat dengan melarutkan 2,250 g TPP dalam $15 \mathrm{~mL}$ asam asetat glasial dan atau asam asetat $4 \%$ sampai $\mathrm{pH}$ sesuai formula, dimasukkan dalam emulsi yang telah terbentuk dengan kecepatan konstan selama 5 menit selanjutnya diaduk dengan kecepatan $500 \mathrm{rpm}$ selama 30 menit. Mikropartikel yang terbentuk kemudian disaring dengan corong Buchner serta dicuci dengan menggunakan washbenzene sebanyak 5 kali $( \pm 20 \mathrm{~mL})$. kemudian dicuci dengan akuades dingin sebanyak 3 kali ( $\pm 20 \mathrm{~mL}$ ). Mikropartikel dikeringkan dalam oven suhu $40{ }^{\circ} \mathrm{C}$ selama 65 menit (Rijal, dkk, 2010).

Evaluasi Mikropartikel

a. Pengukuran ukuran, bentuk dan permukaan partikel dengan Scanning Electron Microscopy (SEM)
Pengukuran ukuran, bentuk dan permukaan partikel dilakukan dengan menggunakan metode SEM. Sampel yang ditempelkan dengan menggunakan conducting glue pada sample holder. Lalu dilakukan coating untuk melapisi sampel dengan Pt dan $\mathrm{Au}$ agar sampel tidak rusak saat discanning. Kemudian lakukan scanning (Anggraeni, 2008).

b. Karakteristik Gugus Fungsi dengan

Fourier Transform Infra Red (FTIR)

Karakteristik dilakukan dengan membandingkan spektrum inframerah ketoprofen, kitosan tripolifosfat (mikropartikel ketoprofen). Hal ini dilakukan untuk mengetahui apakah ada senyawa baru yang terbentuk atau tidak. Sampel yang telah dikompres, kemudian scan pada resolusi $2 \mathrm{~cm}^{-1}$ dari 4000 sampai $200 \mathrm{~cm}^{-1}$ (Grimling, et al., 2014).

c. Uji Kandungan Ibuprofen dengan Spektrofotometer Uv-Vis

Pengujian kandungan ibuprofen dalam mikropartikel dilakukan dengan Spektrofotometer UV-Vis pada panjang gelombang lebih kurang 264 $\mathrm{nm}$ dan $273 \mathrm{~nm}$ tidak berbeda lebih dari 3,0\% untuk menetapkan 
konsentrasi obat bebas (yang tidak terjerap). Persentase obat yang terjerap dihitung dengan rumus, yaitu:

$$
\begin{aligned}
& \% \text { kandungan zat aktif } \\
& \qquad=\left\{\frac{\text { bobot yang didapat }}{\text { bobot yang ditimbang }}\right\} \times 100 \%
\end{aligned}
$$

\section{d. Uji Kelarutan}

Uji kelarutan dilakukan pada suhu $25^{\circ} \pm 1{ }^{\circ} \mathrm{C}$ dalam medium air selama 48 jam. Suspensi disaring menggunakan millipore filter $(0,45$ $\mu \mathrm{m})$. Hasil filtrat dianalisis menggunakan Spektrofotometer UvVis pada panjang gelombang maksimum ibuprofen (Momoh et al, 2014).

\section{e. Uji Disolusi Mikropartikel}

Uji pelepasan dilakukan dengan metode disolusi partikulat, uji dilakukan selama 60 menit dengan medium dapar dengan $\mathrm{pH} 1,2 ; \mathrm{pH} 4,5$; $\mathrm{pH}$ 6,8; tipe alat disolusi 2 (paddle) dengan kecepatan $50 \mathrm{rpm}$ pada suhu $37^{\circ} \pm 1^{\circ} \mathrm{C}$. Ibuprofen yang telah bercampur dengan media disolusi dalam labu disolusi diambil $5 \mathrm{~mL}$ pada menit ke-5, 10, 15, 20,30, 45, dan 60 menggunakan syringe yang dilengkapi membran filter $0,45 \mu \mathrm{m}$. Sebanyak 5 $\mathrm{mL}$ disolusi murni di tambahkan ke dalam campuran ibuprofen dan media disolusi. Hasil uji disolusi dianalisis menggunakan spektrofotometer UVVis pada panjang gelombang maksimum ibuprofen (Food and Drug Administration, 2000).

\section{Hasil dan Pembahasan}

Proses Pembentukan Mikropartikel
Proses pembuatan dari mikropartikel dengan menggunakan metode emulsification ionic-gelation. Dari hasil pembentukan mikropartikel metode emulsification ionic-gelation diperoleh partikel halus berwarna putih. Dalam metode ini digunakan optimasi $\mathrm{pH}$ yaitu $\mathrm{pH} 2, \mathrm{pH} 4$, dan $\mathrm{pH}$ 6. Tujuan dari optimasi $\mathrm{pH}$ ini adalah untuk mengetahui terbentuknya ikatan crosslink yang paling optimal dari ketiga $\mathrm{pH}$ tersebut. Bahan-bahan yang digunakan dalam penelitian ini adalah ibuprofen sebagai zat aktif, polivinil alkohol (PVA) sebagai polimer yang akan menyelubungi zat aktif, Tripolifophat (TPP) sebagai agen crosslink, asam asetat sebagai katalis reaksi crosslink serta sebagai pelarut PVA, dan VCO sebagai agen emulsi. Semua bahan-bahan tersebut selanjutnya dilakukan pengadukan dengan kecepatan tinggi dengan kecepatan 7000 rpm dalam waktu 45 menit, dengan urutan sebagai berikut, ibuprofen didispersikan kedalam PVA, selanjutnya di tambahkan TPP, dan terakhir VCO. Penambahan TPP sebelum VCO dimaksudkan agar TPP berikatan secara maksimal dengan PVA sehingga memaksimalkan reaksi crosslink. Dalam pengadukan yang tinggi partikel ibuprofen akan terpecah menjadi globul-globul yang memiliki ukuran yang lebih kecil yang akan bereaksi dengan ikatan crosslink antara PVA-TPP. Penurunan ukuran partikel yang terjadi tersebut menyebabkan luas permukaan antar partikel menjadi bertambah sehingga menyebabkan kelarutan nya akan meningkat. 


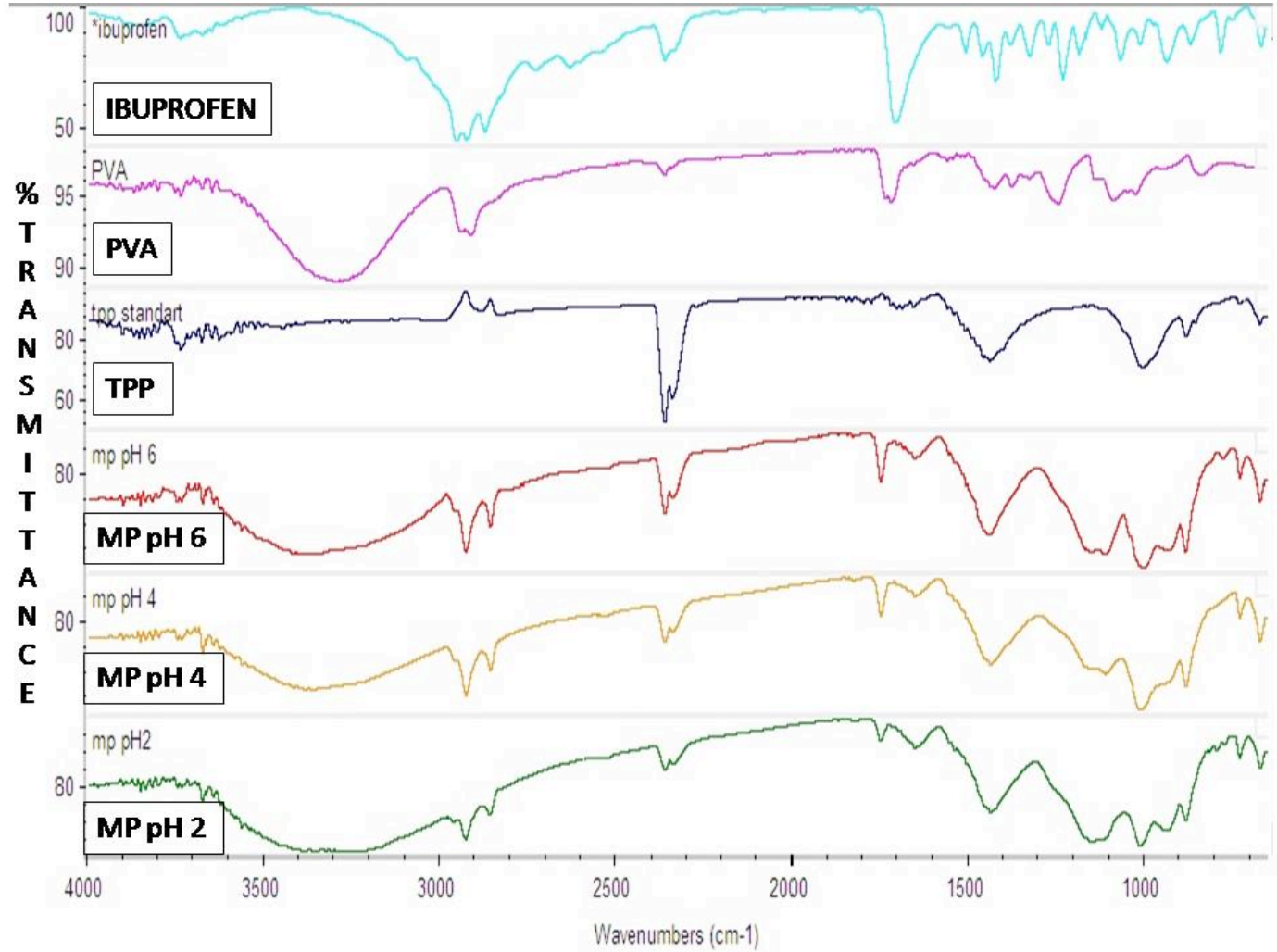

Gambar 1. Hasil Karakterisasi Ibuprofen Menggunakan Spektrofotometer Fourier Transform Infrared (FT-IR)

Karakterisasi Mikropartikel

Gugus Fungsi Mikropartikel

Hasil karakterisasi ibuprofen menggunakan spektrofotometer fourier transform infrared (FT-IR) dapat dilihat pada gambar 1 .

Pemeriksaan mikropartikel dengan menggunakan spektrofotometer Fourier Transform Infrared (FT-IR) ini bertujuan untuk melihat terbentuknya ikatan sambung silang antara PVA dengan TPP yang menandakan bahwa proses pembentukan mikropartikel telah terjadi dan untuk mengetahui apakah ada perubahan puncak masing-masing gugus khas pada setiap zat yang terdapat dalam campuran mikropartikel yang telah mengalami proses emulsification-ionic-gelation.

Ditandai ikatan sambung silang dari PVA dan TPP telah terjadi ditandai dengan terbentuknya senyawa baru pada bilangan gelombang 1100 $\mathrm{cm}^{-1}$ yaitu gugus C-O ester. Dalam hal ini gugus $\mathrm{O}-\mathrm{H}$ dari PVA akan berikatan dengan gugus $\mathrm{P}-\mathrm{O}$ dari TPP dan akan membentuk suatu ester. Untuk puncak-puncak yang menandai spektrum khas dari ibuprofen pada mikropartikel terletak pada bilangan gelombang $1735 \mathrm{~cm}^{-1}$ menandai adanya gugus $\mathrm{C}=\mathrm{O}$ karboksilat yang merupakan salah satu gugus khas yang ada didalam struktur ibuprofen. Dari 
hasil FT-IR terlihat bahwa gugus $\mathrm{C}=\mathrm{O}$ yang berada di dalam mikropartikel pada semua $\mathrm{pH}$ mengalami pergeseran ke arah bilangan gelombang yang lebih besar. Selain itu, spektrum khas dari ibuprofen dalam mikropartikel setelah emulsification ionic-gelation ditandai dengan adanya gugus $\mathrm{C}=\mathrm{H}$ benzen yang terletak pada bilangan gelombang $2900 \mathrm{~cm}^{-1}$, tidak terjadi pergeseran dari puncak sebelumnya. Untuk spektrum khas dari PVA dalam mikropartikel setelah emulsification ionic-gelation, ditandai dengan adanya gugus $\mathrm{O}-\mathrm{H}$ pada bilangan gelombang
$3200 \mathrm{~cm}^{-1}$ gugus $\mathrm{O}-\mathrm{H}$ mengalami pergeseran kebilangan yang lebih besar. Kemudian, untuk spektrum khas dari TPP dalam mikropartikel setelah emulsification ionic-gelation ditandai dengan adanya gugus $\mathrm{P}-\mathrm{O}$ pada panjang bilangan gelombang 1002,83 $\mathrm{cm}^{-1}$ dalam hal ini tidak ada pergeseran dari puncak awal.

Ukuran Dan Morfologi Mikropartikel

Hasil karakterisasi ibuprofen menggunakan scanning electron microscopy dapat dilihat pada Gambar 2.
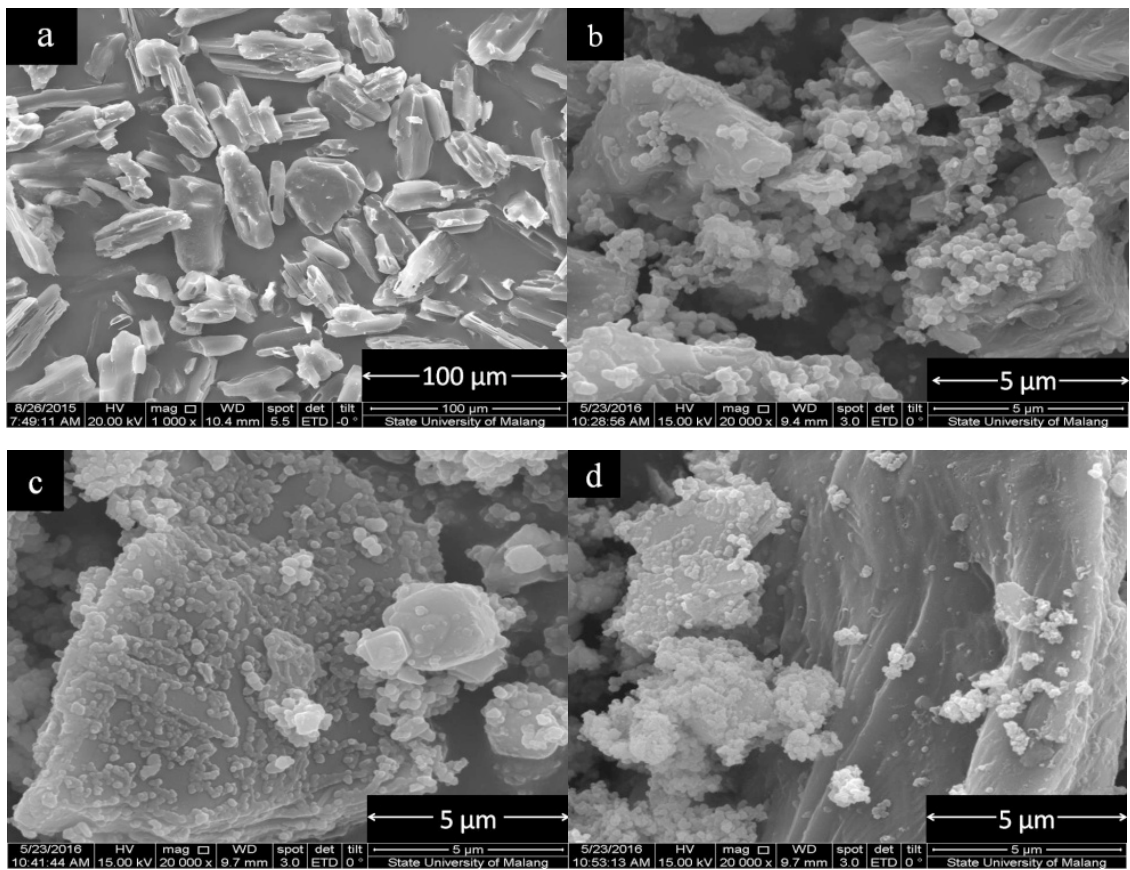

Gambar 2. SEM (a) ibuprofen, (b) mikropartikel F1, (c) mikropartikel F2, dan (d) mikropartikel F3. 
Berdasarkan gambar 2. (a) ibuprofen sebelum melewati proses emulsification ionic-gelation berbentuk batang dengan sisi runcing, sedangkan berdasarkan gambar 2. (b), (c), dan (d) setelah melewati proses pembentukan mikropartikel dengan metode emulsification ionic-gelation terlihat bahwa partikel primer ibuprofen dikelilingi oleh partikelpartikel berbentuk bulat. Terbentuknya partikel-partikel tersebut merupakan hasil dari reaksi ikatan crosslink antara polivinil alkohol dan tripolifosfat yang mengelilingi ibuprofen untuk membentuk partikel dengan ikatan stabil yang terbentuk melalui proses emulsification ionic-gelation.

Terbentuknya partikel-partikel tersebut merupakan hasil dari reaksi ikatan crosslink antara PVA dan TPP yang mengelilingi ibuprofen untuk membentuk partikel dengan ikatan stabil yang terbentuk melalui proses emulsification-ionic-gelation. Hasil penurunan ukuran partikel dari ibuprofen setelah proses emulsification-ionic-gelation dapat dilihat pada Tabel 2.

Tabel 2. Hasil Pengukuran Ukuran Partikel dengan Scanning Electron Microscopy

\begin{tabular}{cc}
\hline Sampel & $\begin{array}{c}\text { Ukuran Partikel } \\
(\boldsymbol{\mu m})\end{array}$ \\
\hline Ibuprofen & 58,2667 \\
F1 & 1,468 \\
F2 & 1,782 \\
F3 & 2,254 \\
\hline
\end{tabular}

Berdasarkan karakteristik menggunakan SEM, ukuran partikel ibuprofen setelah proses emulsification ionic-gelation mengalami penurunan dari ukuran partikel. Terlihat pada tabel 2 partikel mikropartikel $\mathrm{pH} 2$, $\mathrm{pH} 4$, pH 6 mengalami penurunan ukuran partikel berturut-turut sebesar $97,48 \%$, 84\%, dan $72 \%$ dari ukuran ibuprofen sebelum proses emulsification ionic-gelation. Penurunan ukuran partikel dari ibuprofen disebabkan karena dalam proses emulsification-ionic-gelation melewati tahap homogenizing yaitu pengadukan dengan kecepatan tinggi (5.000-10.000 rpm). Pada tahap tersebut ibuprofen akan terpecah menjadi globul-globul sehingga menurunkan ukuran partikelnya. Untuk menjadikannya partikel yang stabil maka globul-globul tersebut akan dilapisi oleh PVA dan TPP yang sebelumnya sudah membentuk suatu ikatan yang dinamakan crosslink.

Uji Kandungan Obat Hasil uji kandungan ibuprofen setelah proses emulsification ionicgelation dapat dilihat pada Tabel 3.

Tabel 3. Hasil Uji Kandungan Ibuprofen

\begin{tabular}{cc}
\hline Sampel & $\begin{array}{c}\text { Kandungan } \\
\text { Ibuprofen }(\boldsymbol{\mu g} / \mathbf{m L})\end{array}$ \\
\hline F1 & 5,812 \\
F2 & 12,75 \\
F3 & 13,25 \\
\hline
\end{tabular}


Kandungan ibuprofen dalam partikel ibuprofen setelah proses emulsification ionic-gelation perlu diketahui untuk penyetaraan kadar ibuprofen saat pengujian kelarutan dan difusi. Berdasarkan hasil uji kandungan, kadar ibuprofen setelah proses emulsification ionic-gelation yang terbesar adalah 13,25 ppm pada mikropartikel dengan $\mathrm{pH}$ 6. Hal tersebut kemungkinan terjadi karena dalam $\mathrm{pH}$ yang tidak terlalu asam ion tripolifosfat sebagai crosslink tidak hanya melepaskan ion tripolifosfat dalam reaksi tetapi juga melepaskan ion hidroksil yang saling berkompetisi untuk berikatan dengan ion $\mathrm{OH}^{2+}$ (Bhumkar dan Pokharkar, 2006). Hal ini membuat crosslink dapat berikatan secara optimal dibandingkan dengan ikatan di $\mathrm{pH}$ asam dan hal ini berpengaruh terhadap penjerapan ibuprofen yang jumlah penjerapannya semakin besar di dalam $\mathrm{pH}$ asam lemah.

Uji Implementasi Mikropartikel

A. Uji Kelarutan

Hasil uji kelarutan Ibuprofen sebelum dan sesudah proses emulsification ionic gelation dapat dilihat pada Tabel 4.

Tabel 4. Hasil Uji Kelarutan Ibuprofen Sebelum dan Setelah Proses Emulsification-Ionic Gelation dalam Air.

\begin{tabular}{cc}
\hline Sampel & Kadar Terlarut $(\boldsymbol{\mu g} / \mathbf{m l})$ \\
\hline Ibuprofen & 10,95 \\
F1 & 63,2 \\
F2 & 72,4 \\
F3 & 88,49 \\
\hline
\end{tabular}

Berdasarkan data pada Tabel 4. partikel setelah emulsification ionicgelation memiliki kelarutan dalam air lebih tinggi dibandingkan dengan ibuprofen sebelum proses emulsification ionic-gelation. Hal tersebut disebabkan oleh ukuran partikel dari ibuprofen setelah proses emulsification ionic-gelation yang mengalami penurunan ukuran, sehingga perbandingan luas permukaan dan volume kontaknya lebih besar, semakin kecil ukuran partikel maka semakin besar luas permukaannya. Luas permukaan partikel yang besar menyebabkan permukaan kontak partikel dengan air menjadi besar sehingga kelarutan partikel setelah emulsification ionicgelation dalam air meningkat.

Secara berturut-turut kelarutan partikel setelah emulsification ionicgelation untuk formula F1, F2, dan F3 meningkat 6 kali, 7 kali, dan 8 kali lebih tinggi dibandingkan dengan kelarutan ibuprofen sebelum emulsification ionic-gelation.

\section{B. Hasil Uji Disolusi Partikulat}

Pada uji disolusi partikulat digunakan tiga media dapar yang berbeda, yaitu dapar $\mathrm{pH} 1,2$, dapar asetat $\mathrm{pH} 4,5$, dan dapar fosfat $\mathrm{pH} 6,8$. Media ini digunakan untuk menyesuaikan $\mathrm{pH}$ saluran gastrointestinal. Media asam atau $\mathrm{HCl}$ $0,1 \mathrm{~N}$ digunakan untuk menyesuaikan komposisi cairan lambung. Dapar asetat $\mathrm{pH} \quad 4,5$ digunakan untuk menyesuaikan $\mathrm{pH}$ duodenum yang merupakan peralihan antara cairan lambung dan usus. Dapar alkali atau fosfat $\mathrm{pH} \quad 6,8$ digunakan untuk menyesuaikan $\mathrm{pH}$ usus. Temperatur 
yang digunakan pada uji disolusi partikulat ini adalah $37^{\circ} \mathrm{C} \pm 1^{\circ} \mathrm{C}$ sesuai dengan temperatur tubuh manusia.
Hasil uji disolusi partikulat ibuprofen sebelum dan sesudah proses emulsification ionic-gelation dalam media $\mathrm{HCl} 0,1 \mathrm{~N}$ dapat dilihat pada gambar 3 .

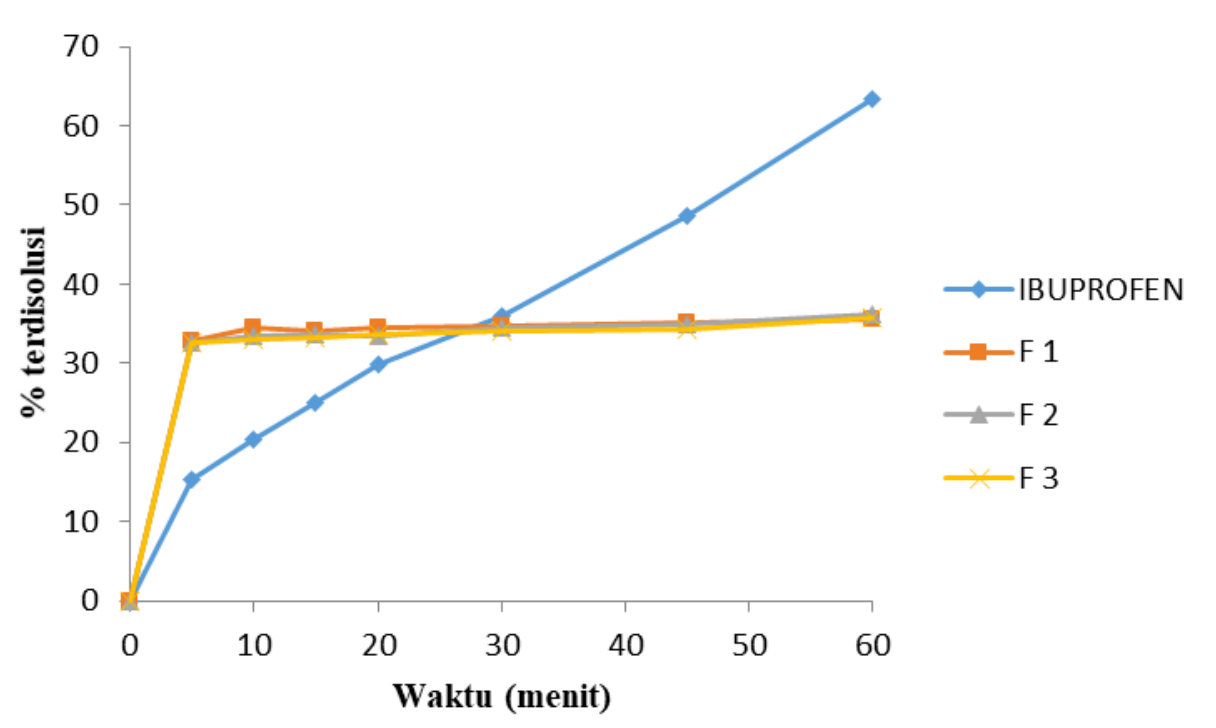

Gambar 3. Profil Disolusi Ibuprofen dalam Media Dapar HCl 0,1 N

Dalam media dapar $\mathrm{HCl} 0,1 \mathrm{~N}$ partikel ibuprofen setelah proses emulsification-ionic-gelation terdisolusi tidak lebih baik dibandingkan dengan ibuprofen sebelum proses emulsification-ionicgelation, ibuprofen sebelum dan setelah proses emulsification-ionic- gelation terdisolusi kurang dari $85 \%$ dalam media dapar $\mathrm{HCl} 0,1 \mathrm{~N}$.

Hasil uji disolusi partikulat ibuprofen sebelum dan setelah proses emulsification-ionic-gelation dalam media dapar asetat $\mathrm{pH}$ 4,5 dapat dilihat pada gambar 4 . 


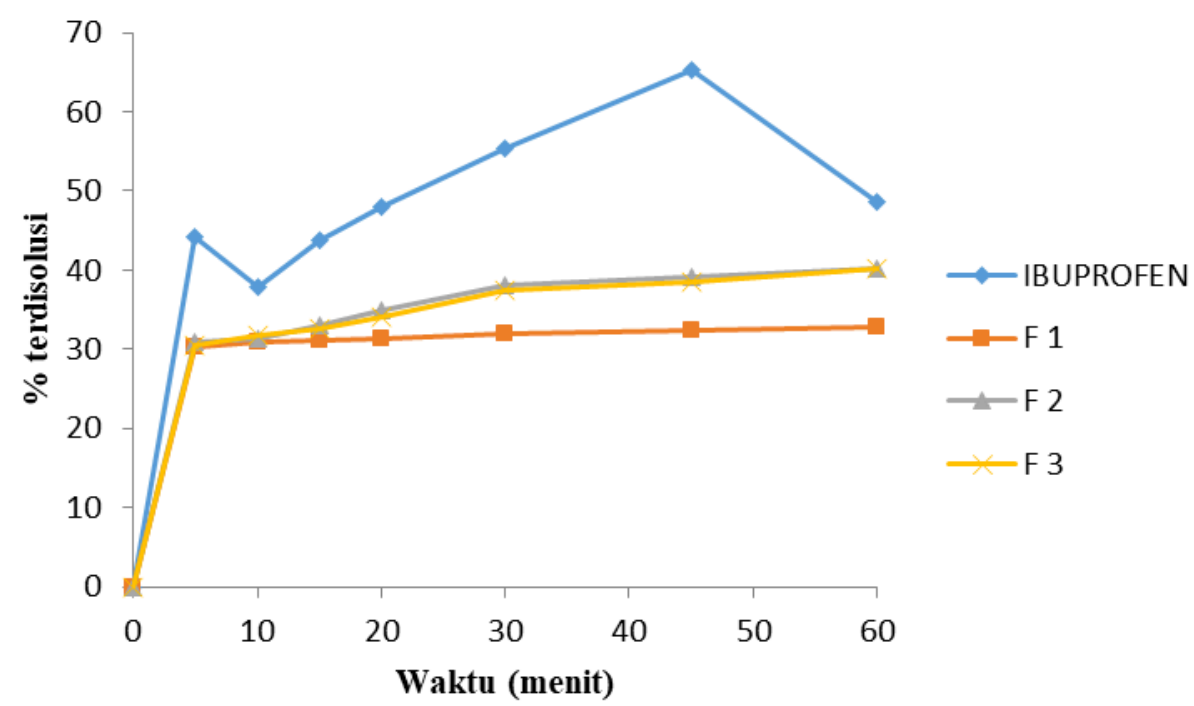

Gambar 4. Profil Disolusi Ibuprofen dalam Media Dapar Asetat pH 4,5.

Dalam media dapar Asetat $\mathrm{pH}$ 4,5 partikel ibuprofen setelah proses emulsification-ionic-gelation terdisolusi tidak lebih baik dibandingkan dengan ibuprofen sebelum proses emulsification-ionicgelation, ibuprofen sebelum dan setelah proses emulsification-ionic- gelation terdisolusi kurang dari $85 \%$ dalam media dapar Asetat $\mathrm{pH} 4,5$.

Hasil uji disolusi partikulat ibuprofen sebelum dan sesudah proses emulsification-ionic-gelation dalam media dapar fosfat $\mathrm{pH}$ 6,8 dapat dilihat pada gambar 5 .

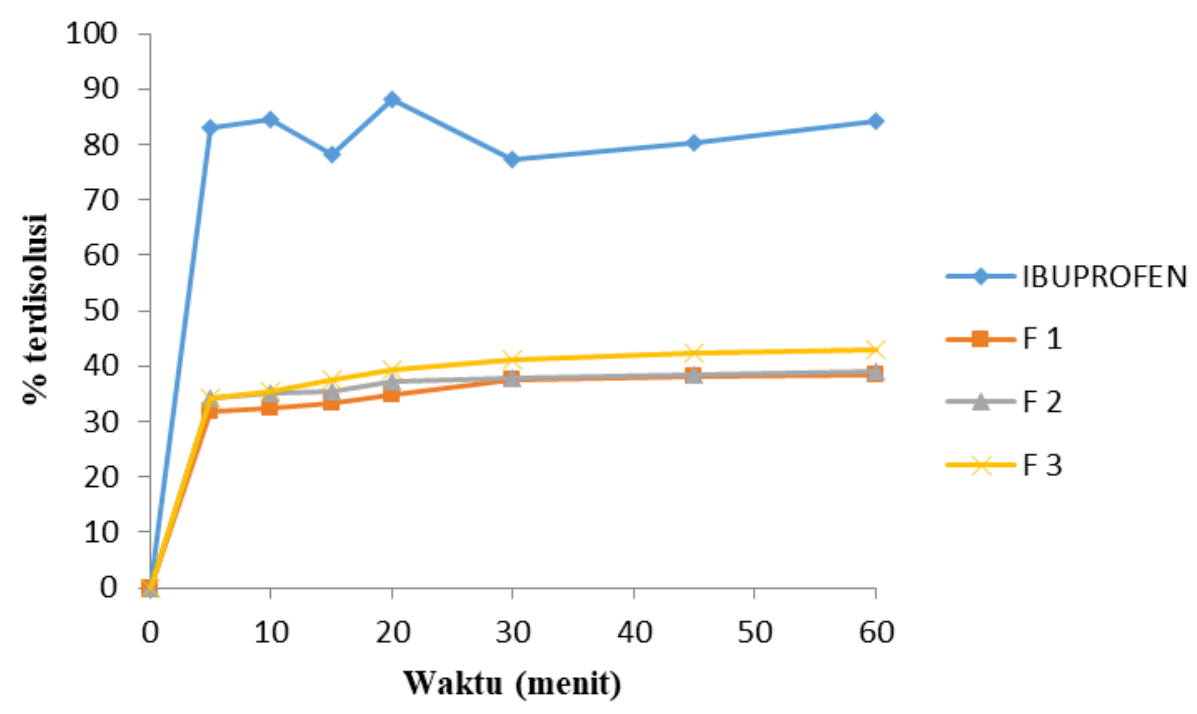

Gambar 5. Profil Disolusi Ibuprofen dalam Media Dapar Fosfat pH 6,8. 
Dalam media dapar fosfat $\mathrm{pH}$ 6,8, partikel ibuprofen setelah proses emulsification-ionic-gelation

terdisolusi tidak lebih baik dibandingkan dengan ibuprofen sebelum proses emulsification-ionicgelation, ibuprofen sebelum dan

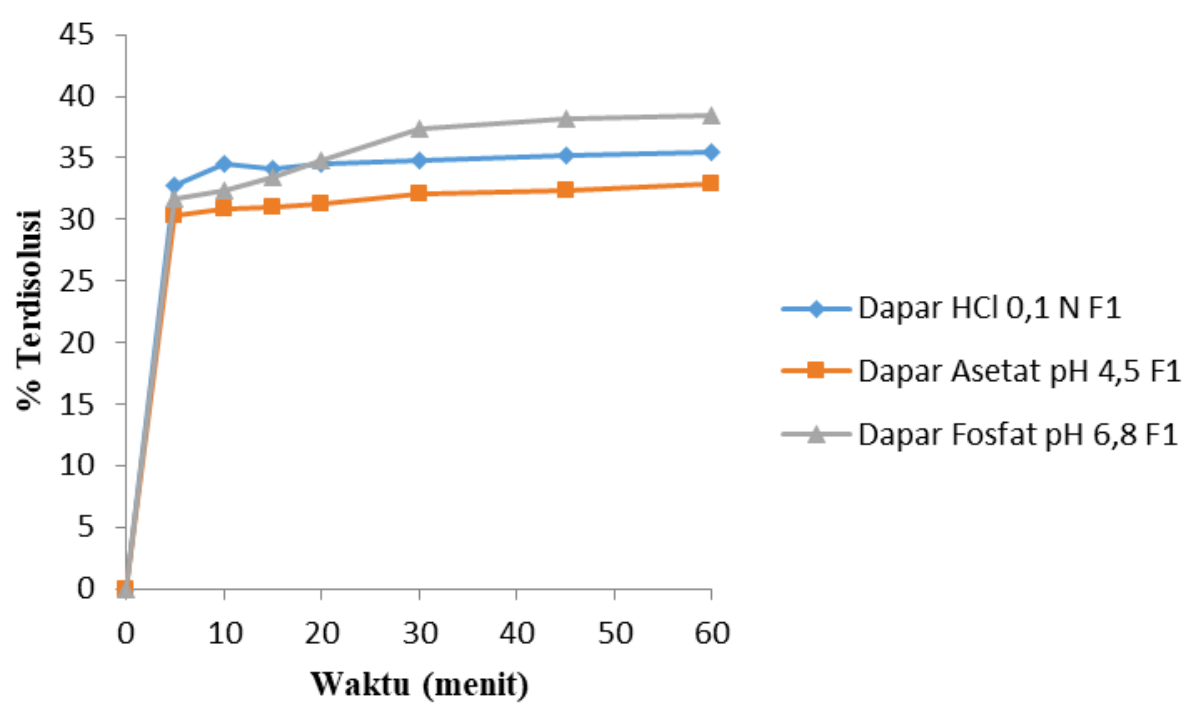

Gambar 6. Profil Disolusi Partikel Ibuprofen F1 pada Berbagai Media Disolusi

Disolusi partikel ibuprofen setelah proses emulsification-ionicgelation F1 lebih tinggi dalam media dapar fosfat $\mathrm{pH} \quad 6,8$ dibandingkan dengan media dapar yang lain.

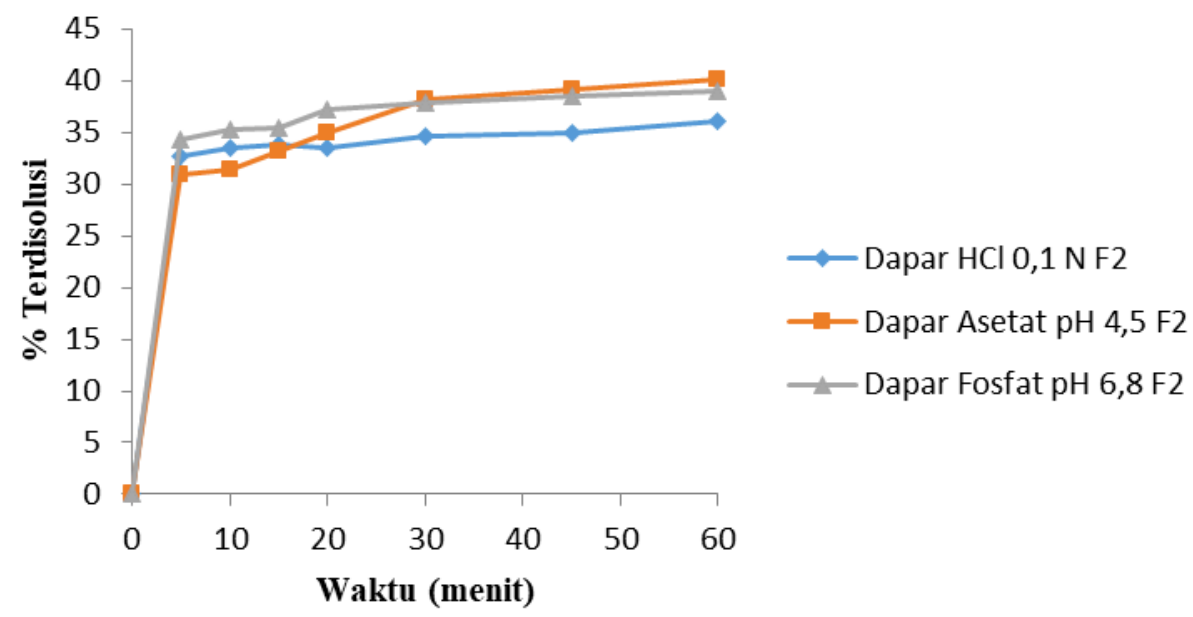


Gambar 7. Profil Disolusi Partikel Ibuprofen F2 pada Berbagai Media Disolusi

Disolusi partikel ibuprofen dengan media dapar yang lain. Hasil setelah proses emulsification-ionic- uji disolusi partikulat dalam ketiga gelation F2 lebih tinggi dalam media media dapar dari formula 3 (F3)dapat dapar fosfat $\mathrm{pH}$ 6,8 dibandingkan dilihat pada Gambar 8.

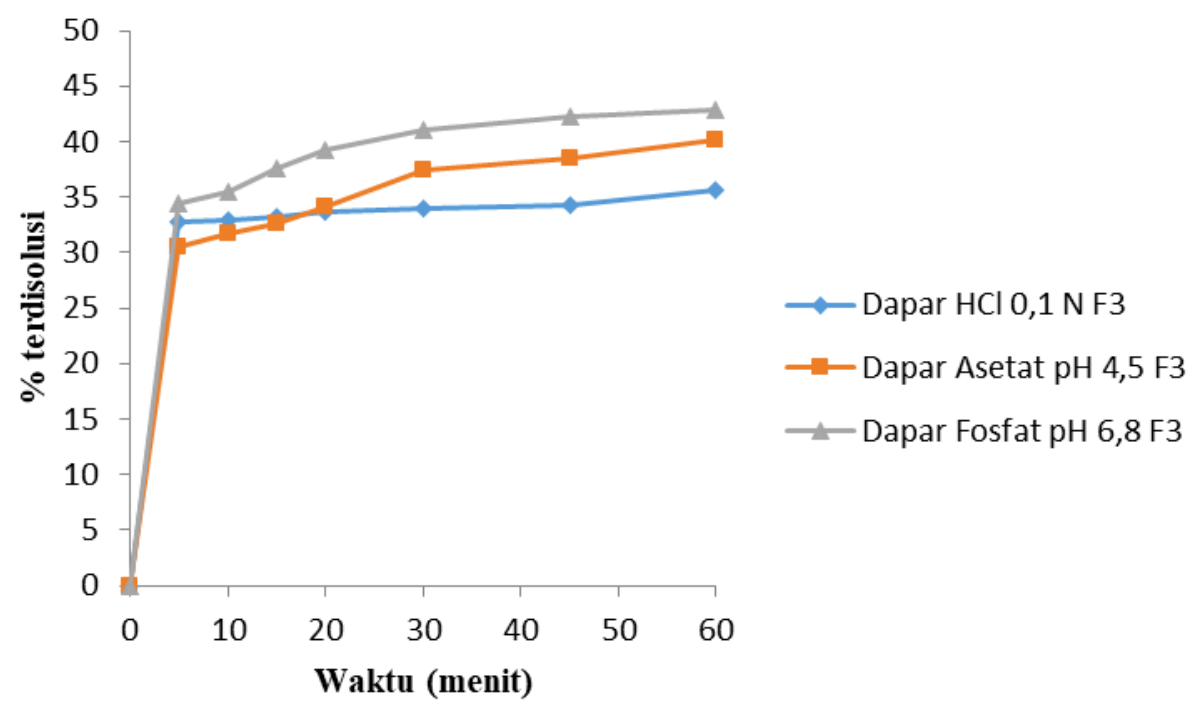

Gambar 8. Profil Disolusi Partikel Ibuprofen F3 pada Berbagai Media Disolusi. 
Disolusi partikel ibuprofen setelah proses emulsification-ionic-gelation F3 lebih tinggi dalam media dapar fosfat $\mathrm{pH}$ 6,8 dibandingkan dengan media dapar yang lain.

Berdasarkan media dapar yang digunakan dalam uji disolusi, disolusi partikel ibuprofen setelah proses emulsification-ionic-gelation dari yang tertinggi hingga ke yang paling rendah adalah dapar fosfat $\mathrm{pH} 6,8$, dapar asetat $\mathrm{pH}$ 4,5, dan $\mathrm{HCl} 0,1 \mathrm{~N}$. Hal tersebut disebabkan ibuprofen yang bersifat asam lemah lebih mudah larut dalam media basa dibandingkan pada media basa. PVA yang merupakan polimer hidrofilik yang memiliki sifat sulit larut didalam larutan organik, tetapi lebih larut dalam basa lemah. Oleh sebab itu, partikel ibuprofen setelah proses emulsification-ionicgelation lebih mudah terdisolusi dalam media dapar fosfat $\mathrm{pH} 6,8$.

\section{Simpulan}

Berdasarkan penelitian, teknik emulsification-ionic-gelation berhasil membentuk partikel mikro ibuprofen sehingga meningkatkan kelarutan, menurunkan ukuran partikel tetapi tidak meningkatkan disolusi dari ibuprofen.

\section{Daftar Pustaka}

Agnihotri, S.A., and Aminabhavi, T.M. 2004. "Recent advance on chitosan based micro and nanoparticles in drug delivery." J. Of Controlled Release 100: 6-18.

Anggraeni, D.N. 2008. "Analisis SEM (Scanning Electron Microscopy) dalam Pemantauan Proses Oksidasi Magnetite Menjadi Hematite". Seminar Nasional - VII. Bandung. Hal 51-53.

Bhumkar, D.R., and Pokharkar, V.B. 2006. "Studies on Effect of $\mathrm{pH}$ on Crosslinkingof Chitosan with Natrium Tripolyphosphate". India: AAPS Pharm Seci Tech 7(2): 1-6.
BPOM. 2009. Prosedur Operasional Baku Uji Toksisitas Praklinik. Jakarta : Pusat Riset Obat dan Makanan Badan Pengawasan Obat dan Makanan Republik Indonesia. Hal 96-99.

Champagne, L.M. 2008. "The Synthesis of Water Soluble n-acyl Chitosan Derivates FOR Characterization as Antibacterial Agents." Disertasi. The Departement of Chemistry, B.S Xavier University of Lourisiana. pp.1-2.

Departemen Kesehatan RI. 2014. Farmakope Indonesia Edisi 4. Jakarta: Departemen Kesehatan Republik Indonesia. Hal 449.

Dressman, J., and Butler, J. 2001. The Biopharmaceutical Classification System. $\quad$ Www.pharmaportal.com diakses pada tanggal 25 Juni 2015. Hal 70-71.

Food and Drug Administration. 2000. "Guidance For Industry : Waiver Of In Vivo Bioavailablity and Bioequivalance Studies For Immediate-Release Solid Oral Dossage Forms Based On a Biopharmaceutis Classification System." US Departement Of Health and Human Services. Pp. 1-8.

Grimling, B., Gorniak, A., Meler, J., Szczesniak, M., and Pluta, J. 2014. "Characterisation and Dissolution Properties Of Ketopropen In Binary Solid Dispersion With Chitosan." Progress on Chemistry and application of chitin and its Derivatives 19: 23-32.

Ko, J.A., Hwang, S. J., Park, J. B., and Lee, J.S. 2002. "Preparation and characterization of chitosan microparticles intende for controlled drug delivery." International Journal Pharm : 165-174. 
Kumar, B.P., Chandiran, I.S., Bhavya, B., and Sindhuri, M. 2011. "Microparticulate Drug Delivery System: A Review." Indian Journal of Pharmaceutical Science and Research (I): 19-37.

Lie, X.Y., Kong, X.Y., Shi, S., Zheng, X.L., Guo, G., Wei, Y.Q. 2008. "Preparation of alginate coated chitosan microparticle for vaccine delivery". BMC Biotechnology. Pp. 88-89.

Mallick, J., Sahoo, D., Kar,D.M., and Makwana,J. 2013. “Alginate beads of ibuprofen for oral sustained drug delivery : an in vitro evaluation." IJPCBS, 3(3): 595-602.

Momoh, MA., Adedokun, MO., Lawal, SB., and Ubochi, GO. 2014. "Formulation and In vitro Evaluation of Ibuprofen-Loaded Poly(D,L-lactide-co-glycolide) Microparticles" Tropical Journal of Pharmaceutical 13 (10): 1571-1576.

Nafrialdi dan Setawati, A. 2007. Farmakologi dan Terapi. Edisi 5. Jakarta: Departemen Farmakologi dan Terapeutik Fakultas Kedokteran UI. Hal 467-481.

Nur, I.S. 2011. "Preparasi dan Karakterisasi Kitosan-Tripolifosfat Sebagai Eksipien dalam Sediaan Farmasi." Skripsi. Jurusan Farmasi FMIPA Universitas Indonesia. Depok. Hal 4-6.

Parida, K., Panda, S., Ravanan, P., Roy, H., Manickam, M., Talwar, P. 2013. "Microparticles Based Drug Delivery Systes: Preparation and Application in Cancer Therapeutics." International Archieve of Applied Science and Technology 4(3): 68-75.

Rahman, L., Ismail, I., dan Wahyudin, E. 2011. "Kapasitas Jerap Niosom Terhadap Ketoprofen dan Prediksi
Penggunaan Transdermal." Majalah Farmasi Indonesia 22(2): 85-91.

Rakhmaningtyas, WA. 2012. "Preparasi Dan Karakterisasi Nanopartikel Sambung Silang Kitosan-Natrium Tripolifosfat Dalam Sediaan Film Bukal Verapamil Hidroklorida" Skripsi. Fakultas Matematika Dan Ilmu Pengetahuan Alam Program Studi Ekstensi Farmasi. Depok. Hal 8-12.

Rijal, M.A.S., Mikail, A., dan Sari, R. 2010. "Pengaruh pH Larutan Tripolifosfat Terhadap Karakteristik Fisik SertaProfil PelepasanMikropartikel TeofilinChitosan."Majalah Farmasi Airlangga 8(2) : 28-29.

Rowe, R.C., Sheskey, P.J., and Quinn, M. 2009. Handbook of Pharmaceutical Excipients SixthEdition. USA: Pharmaceutical Press and American Pharmacist Association. Pp. 195.

Samad, A., Tariq, M., Alam, M.I., and Akhter, M. S. 2010. "Collloid in Drug Delivery." Microsphere A Novel Drug Delivery System. Taylor and Francis Group, LLC. Pp 456463.

Shrestha,B., Prakash Rath, J.2013." Poly(vinyl alcohol)-coated chitosan microparticles act as an effective oral vaccine delivery system for hepatitis B vaccine in rat model." The Institution of Engineering and Technology Nanobiotechnol. pp. 17.

Shohin, I.E., Kulinich, J.I., Ramenskaya, G.V., Abrahamsson, B., Kopp, S., Langguth, P., Polli, J.E., Shah, V.P., Groot, D.W., Barends, D.M., and Dressman, J.B. 2012. "Monographs for immediate-release solid oral dosage forms: Ketoprofen." $J$. Pharm. Science 101: 3593-3603. 
Shivhare,UD., Singare,SS., Mathur, VB.2014. " Formulation And Evaluation Of Microspheres For Immediate And Sustained Release Of Different Drugs Using Same Polymer." International Journal of Pharmaceutical Development and technology 4(1), 2014, 1-7.

Sinko, J. 2011. Martin Farmasi Fisika \& Ilmu Farmasetika, edisi 5. (Diterjemahkan oleh: Joshita Djajadisastra dan Amalia $\mathrm{H}$. Hadinata). Jakarta: EGC. Hal 438439.

Swasono, R.T., Erizal, E., and Hendriyanto, H. 2006. Jurnal Sains dan Technology Nuklir Indonesia. Hal 1-16.

USP 32-NF 27. 2009. United States Pharmacopeia and The National
Formulary. Rockville (MD): The United States Pharmacopeial Convention. Pp 557.

Wijaya, D.P. 2013. "Preparasi Nanopartikel Sambung Silang Kitosan-Tripolifosfar yang Mengandung Ginsenosida." Skripsi. Jurusan Farmasi Fakultas Kedokteran dan Ilmu Kesehatan Universitas Syarif Hidayatullah. Jakarta. Hal 10-11.

Widyaningsih, Linda. 2009. "Pengaruh Penambahan Kosolven Propilen Glikol terhadap Kelarutan Asam Mefenamat". Skripsi. Fakultas Farmasi Universitas Muhammadiyah. Surakarta. Hal 3-4, 8-12. 